\title{
The economic and energy efficiencies of GCC states: A DEA approach
}

\section{Mohammad Imdadul Haque*}

Associate Professor, CBAK, P.O.Box: 165, Prince Sattam Bin Abdulaziz University, Al Kharj, Saudi Arabia

\begin{tabular}{l}
\hline C H R O N I C L E \\
\hline Article history: \\
Received: October 5, 2018 \\
Received in revised format: Octo- \\
ber 8, 2018 \\
Accepted: November 12, 2018 \\
Available online: \\
November 12, 2018 \\
\hline Keywords: \\
Economic efficiency \\
Energy efficiency \\
CO2 emissions \\
GCC \\
DEA
\end{tabular}

\section{Introduction}

Energy is now identified as a factor of production like labor and capital. Energy consumption is now considered as an indicator of economic development (Stern, 1998; Halicioglu, 2009; Ucan et.al, 2014). High economic development needs higher energy consumption. Simultaneously, efficient energy consumption requires high economic development. To make economic development sustainable the relationships between the three 'E's; namely economy, energy and environment have to be considered together. At initial stages of development, environmental quality is not that much important. But once income reaches a certain mark, people start demanding environmental quality. This calls for a judicious use of energy and a need to reduce pollution. Based on the advancement in technology, highly polluting industries can be transformed into less polluting ones. Education and awareness lead to further conservation at household level. Also with a development there is a structural transformation from an industrial

* Corresponding author. Tel.: +966534413574

E-mail address: m.haque@.psau.edu.sa (M. Imdadul Haque)

(C) 2019 by the authors; licensee Growing Science, Canada doi: $10.5267 /$ j.msl.2018.11.005

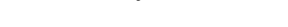


sector which is polluting heavily to a knowledge based service industry which is less polluting and more efficient.

Early models of economic growth did not include energy factors. Like, Solow (1956) talks about technological progress which itself is exogenous to the model. For neoclassical growth models, capital and labor are the principal factors of production. Additionally, neoclassical economists sometimes substituted energy with capital (Solow, 1974). It is assumed by mainstream growth theory that energy plays a minimum role in economic growth. Under conditions of economic efficiency, lower energy usage does not detriment economic growth. Later, Endogenous growth theories explained this technological progress. Economic transformation moved countries from agriculture to industry but energy usage has some harmful consequences such as pollution, global warming and climatic change, etc. Currently, studies like Pablo-Romero and Sánchez-Braza (2015), Fang and Chang (2016) stated that human capital plays an important role for achieving energy efficiency. The Energy Kuznets Curve (EKC) proposes that an inverted U curve exists where in the energy consumption first increases with economic growth and then decreases has gained prominence. Acceptance of EKC implies that there is not any requirement of active conservation strategies as the utilization of relatively inexpensive alternate technologies will lead to reduction of $\mathrm{CO}_{2}$ emissions.

Studies have led to two contrasting views on energy consumption and economic growth. The first view proposes that energy use is a limiting factor to economic growth. Energy consumption is a determining factor for economic growth and for more economic growth, more energy is required. The alternate view proposes that energy is neutral to growth. This 'neutrality hypotheses' suggests 'that the cost of energy is a small proportion of GDP, and so it should not have impact on output growth'. The neutrality hypothesis proposes no relationship between energy consumption and economic growth. This implies that growth and energy consumption are not related. Energy neutrality has been rejected by many researchers (e.g. Ang, 2008; Apergis \& Payne, 2009) and more particularly by Omri (2013) and Howarth et al. (2017) for the GCC countries.

\subsection{The energy sector of GCC}

The six GCC states of Saudi Arabia, Oman, Bahrain, Qatar and UAE share similar economic, geographic and socio-cultural characteristics. Oil is abundant and cheap in these countries and Rainfall and groundwater are scarce. Moreover, harsh climate, extreme temperatures and fertile land unavailability are common. Apart from geographical proximity and similar levels of economic development, these states also have similar challenges regarding energy sector (Sakhrieh, 2016). The economic and demographic characteristics of the GCC countries are blamed for huge energy consumption in these countries. A common vision to reduce its reliance on oil and gas and energy efficiency is an important strategy to achieve this diversification by the GCC states (Howarth, et al., 2017). Vision documents of respective GCC states identify the importance of environment and sustainability. These states have fixed energy and environment related targets. Initiatives like carbon free Masdar city, mandatory efficiency labeling, and star rating for domestic appliances, mandatory building codes show that these states wish to optimize energy consumption.

Table 1

Key Energy Indicators

\begin{tabular}{lccc}
\hline Key Indicators (2015) & GCC average & OECD & WORLD \\
\hline TPES/population (toe/capita) & 10.05 & 4.12 & 1.86 \\
TPES/GDP (toe/thousand 2010 USD) & 0.31 & 0.11 & 0.18 \\
Electricity consumption/population (MWh/capita) & 13.67 & 8.02 & 3.05 \\
CO2/population (t CO2/capita) & 21.72 & 9.18 & 4.4 \\
CO2/GDP (kg CO2/2010 USD) & 0.71 & 0.24 & 0.43 \\
\hline
\end{tabular}

Source: IEA, 2015 
According to Table 1, the ratios of the total primary energy supply (TPES) divided by population, TPES/GDP, Electricity consumption as a ratio to population, the ratio of $\mathrm{CO} 2$ on population and $\mathrm{CO} 2 / \mathrm{GDP}$ for GCC countries are higher than OECD countries and the world average. It is expected that a developing country will have a low use of energy per capita and high use of energy to GDP ratio (WRI, 2014), which signifies that energy is scarce. In developed countries, the energy to GDP ratio is lower but these GCC countries are peculiar and they have high ratio of energy per capita and high energy to GDP ratio. This signifies inefficient consumption of energy.

Apart from industrial usage, energy is required primarily for air conditioning and desalinization (Sultan, 2012). An estimation by Hormann et al. (2012) state that 70 percent of demand for energy in this region is for air-conditioning of the residential and commercial sectors. In their report, Delloite (2015) predicted that the residents of GCC would be with the highest per capita usage of residential electricity by 2035 . As per Sakhrieh (2016) these GCC countries are the main producers of energy and are also the highest per capita consumers of energy. As per Sabouni et al. (2017) total energy consumption in 2015: Industry$31 \%$, Transport- $28 \%$, Residential- $18 \%$. And total final electricity consumption: Residential $-43 \%$, Industry-20\%. As per Al-Sarihi (2018), GCC states have $0.6 \%$ of the world's population while it contributes to 2.4 percent of global emissions. This report is evidence to state that these states have the highest emission per capita. These states are among the world's highest per capita carbon emitters. All the abovenamed studies are of the view that the demand for energy is likely to increase in the coming years in GCC states and the energy efficiency policy and strategies are still in their preliminary stage.

\section{Review of Literature}

Ramanathan (2005) using the data for the year 1996 applied data envelopment techniques (DEA) (Charnes et al., 1984) based on four indicators; namely CO2 emissions per capita, fossil fuel energy consumption, non-fossil fuel energy consumption, and GDP per capita. The GCC countries included in the analysis were Bahrain, Kuwait, Oman, Saudi Arabia, and UAE. Under constant returns to scale, Bahrain and Oman were found to be efficient and Saudi Arabia was found to be the least efficient among the sample of 17 MENA countries. Using Malmquist Productivity Index (MIP) for the period 1992-96, the study reported improvements in efficiency only for Oman among the studied GCC countries. Kuwait had the smallest MPI score indicating it to be the one which is most carbon intensive. Overall, the study indicates that oil rich countries are not efficient and hence are not the ones using carbon friendly energy practices for economic growth and the only exception is Oman.

Al-Iriani (2006) took the data for the GCC states from 1971 to 2001 . Using panel cointegration tests, the relationship between GDP and energy consumption in the GCC states were studied. The study found that there was a unidirectional causal relationship from GDP to energy consumption. There was no causality from energy consumption to GDP. The study opined that these GCC states had huge oil reserves. This has eventually led to an easy access to cheap energy and a high rate of energy consumption. The author senses a lack of serious efforts towards energy conservation. There was also a feeling that energy conservation policies were not in place fearing it would hamper growth. As the causality moves from economic growth to energy consumption, the study recommended that energy conservation could be pursued without any fear of negative impact on growth. On the contrary, energy conservation would lead to the efficient use of energy and finally to further growth. On a different note, the study admitted that studies on energy-economic growth relationships had different results. The author also asserted that empirical studies were not comparable for different countries. Even for a country, the study admitted that, different methodologies and different variables gave different results. He attributed these different results to the difference in socio-economic development pattern.

Mehrara (2007) included all the GCC states except Qatar in his study on MENA countries. Using panel cointegration analysis for the period 1971-2002, the study established strong unidirectional causality from economic growth to energy consumption. The study found long run and short run unidirectional 
causality running from GDP to energy consumption. But energy consumption had a neutral effect on GDP in both short and long run. In a sense, it refutes the neutrality hypothesis of energy income relationship. The study attributed high domestic consumption of energy to low prices. The study established energy as a limiting factor to growth. Hence, the study opines that oil exporting countries will not phase out energy subsidies believing that it would hamper economic growth. Finally, the study recommended revising energy prices so that the environmental quality can be improved without sacrificing economic growth. Energy conservation is a feasible policy with no negative impact on economic growth.

Narayan and Narayan (2010) included all the countries of GCC in their study on 43 countries for the period 1980-2004 using panel cointegration. The study estimated the income elasticity with respect to carbon dioxide emissions. The study tried to find out whether or not the elasticity in the long run is lower than the short run, which implies that $\mathrm{CO} 2$ emissions are decreasing over time with growth. The study found that in the short run income had positive effect on $\mathrm{CO} 2$ emissions in Kuwait, Qatar and Saudi Arabia. A way of judging whether or not $\mathrm{CO} 2$ emissions have been reduced over time with increase in income is by comparing the long run results with the short run. If long run income elasticity is smaller than short run, this means that $\mathrm{CO} 2$ emissions fall with the increase in income. This happened for Kuwait and Qatar. For UAE the results are insignificant. The Error Correction Term (ECT) shows that for all the GCC countries there was a long run relationship between income and $\mathrm{CO} 2$ emissions. The income elasticity was negative for UAE. Except for UAE, some form of pollution control or carbon trading was important for all other countries (where in the long run income has reduced $\mathrm{CO} 2$ emissions). The CO2 emissions have fallen overtime in Kuwait, Qatar, and UAE. Of the countries studied, only the panel of Middle Eastern countries suggests that emissions are lower in the long run as compared with the short run.

Jaunky (2010) studied Bahrain, Oman and UAE for the period 1980-2005 using panel cointegration. The author tried to realize whether or not the long-run elasticity is lower than the short run elasticity, which means that carbon emissions are lowered with economic growth. Thus, such a long-run negative income elasticity of $\mathrm{CO} 2$ emissions validates the EKC hypothesis. Acceptance of EKC hypothesis implies that economic growth is enough to maintain environmental quality. For Bahrain, the study found that income had a positive and significant effect on $\mathrm{CO} 2$ emissions in the short run. But in the long run, it had insignificant long-run income estimation although the ECT was statistically significant. For UAE, the elasticity was negative and significant in the short-run. The long run elasticity was positive but the ECT was not significant indicating absence of long run relationship of $\mathrm{CO} 2$ emissions with income. Bahrain had statistically insignificant long-run income estimations though the ECT was statistically significant. UAE had a long run relationship and statistically significant positive income elasticity. In Oman, there was a long run relationship between $\mathrm{CO} 2$ emissions and income. In the long run, the income elasticity was significant but was insignificant in the short run. As such in the long-run, $\mathrm{CO} 2$ emissions decreased with an increase in income for Oman. This supports the EKC hypothesis for Oman and not for Bahrain and UAE.

Arouri et al. (2012) included Bahrain, Saudi Arabia, Oman, Kuwait, and United Arab Emirates (UAE) in an analysis of MENA countries. The study used panel cointegration to explore the link between GDP, CO2 emissions and energy consumption for 12 countries in the MENA region for the period 1981-2005. The study found a positive relationship between $\mathrm{CO} 2$ emissions and energy consumption and carbon dioxide emissions. For the overall MENA region, an increase of $1 \%$ in energy consumption per capita leads to an increase of $0.47 \%$ carbon dioxide emissions per capita. Also, GDP and carbon dioxide emissions had a quadratic relationship. The study recommended that MENA countries did not need to forgo economic growth to reduce carbon dioxide emission levels as reductions in emissions can be achieved through energy conservation.

Omri (2013) studied 14 countries in the MENA region for the period 1990-2011 including all the 6 GCC countries. Using simultaneous equation models, the study examined the relationship between economic 
growth, energy consumption and $\mathrm{CO} 2$ emissions. The study found bidirectional causality between energy consumption and economic growth and also between economic growth and $\mathrm{CO} 2$ emission. But there was unidirectional causality from energy consumption to $\mathrm{CO} 2$ emissions with no feedback effects. It rejected the neo-classical proposition of energy being neutral to growth. As energy is a determining factor for economic growth and higher growth tend to lead to higher demand for energy. The study opined that energy consumption would enhance economic growth. This meant that there were more consumption of energy leading to more emissions with expansion of production. The study also found bidirectional causality between economic growth and $\mathrm{CO} 2$ emissions. This means that environmental degradation causes economic growth, and a deterioration of environment exerts a negative externality as it effects human health and leads to long run productivity loss.

Howarth et al. (2017) using fixed effects least squares for the period 1990-2014 found that there was a relationship between GDP and energy consumption for the GCC states. A probable reason for this is the low energy prices in these states. It is hypothesized that these low energy prices had dis-incentivized energy efficiency both in households and industry. Contrary to that, it has led to 'distorted patterns of investment' in energy intensive production. The study reports that no decoupling has happened for GCC states and the GDP elasticity of energy consumption for three out of four sectors namely industry, transport and non-energy sector were more than one. This indicates strong relationship between GDP and energy consumption and only for the transport sector it was less than one. The study also reported over time increase in the elasticity of energy consumption and GDP. There has been no evidence of Kuznets type inverted $U$ curve where in the energy consumption first increases with economic growth and then decreases. On the contrary, the GCC states are somewhere on the rising portion of the curve.

The above discussion indicates that there are researches on the energy sector of the GCC states. But to the best knowledge of the authors, there is no study on measuring the energy efficiency of the GCC states, except for Ramanathan (2005) which was based on the data of 1996. This study plans to focus on the economic and energy efficiency of the six GCC states. In the process, the study plans to rank the GCC countries in terms of their efficiency scores. Economic efficiency can be defined as the production of a desirable output out of economic inputs. The current study plans to take GDP as desirable output; and labor and capital as economic inputs. Energy efficiency is described as production of minimum amount of undesirable output on the use of energy inputs. This study plans to take carbon dioxide emissions as undesirable output and electric power consumption and energy use as energy inputs. The remaining of the paper is structured as follows: The next section discusses the methodology and the data to be used. Section four discusses the results and finally section five states the results and the policy recommendation.

\section{Data and Methodology used}

For economic efficiency, gross capital formation (current US\$), GDP, PPP (constant 2011 international $\$$ ), labor force, are used. For energy efficiency total CO2 emissions (kt), electric power consumption (kWh per capita) and energy use (kg of oil equivalent per capita) are used. The sample used in this study covers data of six GCC states. The data for the study is collected for the span of 15 years, from the year 2000 to 2014. Data is collected from World Bank. The study plans to use Data Envelopment Analysis (DEA) for measuring efficiency. DEA is an application of linear programming which can compare different units on the basis of inputs and outputs. The objective of using DEA is to establish that a particular country is less or more efficient compared with other countries. In DEA models, things are simplified to scale in such a way that the total value of a country's input is equal to one. Efficiency is equal to value of output divided by value of inputs. As the inputs are scaled to one, the efficiency of a country will be equal to its output. So, the objective function is to maximize the output which is equal to its efficiency. An important thing is that the units of decision variables have no inherent meaning. In DEA models, the decision variables are stated in terms of unit of each input/output. These are just implicit units and not 
the actual ones. Here the units are relative valuation of inputs and outputs (Taylor). A simple formulation of the problem statement in a DEA model is described below.

For maximization problem:

$\mathrm{DMU}_{\mathrm{j}}$ consumes amount $\mathrm{x}_{\mathrm{ij}}$ of input $i$, where $i=1,2$

$\mathrm{DMU}_{\mathrm{j}}$ produces amount $\mathrm{y}_{\mathrm{rj}}$ of output $r$, where $r=1$

$u r$ is weights assigned to $r^{\text {th }}$ output, where $r=1$

$v_{i}$ is weights assigned to $i^{\text {th }}$ input, where $i=1,2$

where $j=1,2, \ldots, 6$

Let $\mathrm{DMU}_{\mathrm{j}}=\mathrm{DMO}_{\mathrm{o}}\left(\right.$ for $\left.\mathrm{O}^{\text {th }} \mathrm{DMU}\right)$ then

$\max \mathrm{P}_{\mathrm{o}}(\mathrm{u}, \mathrm{v})=\sum_{r} u_{r} y_{r o} / \sum_{i} v_{i} x_{i o}$

subject to,

$\begin{array}{ll}\sum_{r} u_{r} y_{r j} / \sum_{i} v_{i} x_{i j} \leq 1, & \text { for } j=1,2, \ldots, 6 \\ \mathrm{u}_{\mathrm{r}}, \mathrm{v}_{\mathrm{i}} \geq 0, & \text { for all } i \text { and } r\end{array}$

For minimization problem:

$\mathrm{DMU}_{\mathrm{j}}$ consumes amount $\mathrm{w}_{\mathrm{ij}}$ of input $\mathrm{i}$, where $\mathrm{i}=1,2$

$D_{M} U_{j}$ produces amount $z_{r j}$ of output $r$, where $r=1$

$\mathrm{S}_{\mathrm{r}}$ is weights assigned to $\mathrm{r}^{\text {th }}$ output, where $\mathrm{r}=1$

$t_{i}$ is weights assigned to $i^{\text {th }}$ input, where $i=1,2$

Let $\mathrm{DMU}_{\mathrm{j}}=\mathrm{DMO}_{\mathrm{o}} \quad\left(\right.$ for $\left.\mathrm{O}^{\text {th }} \mathrm{DMU}\right)$ where $\mathrm{j}=1,2, \ldots ., 6$

$\min \mathrm{Q}_{\mathrm{o}}(\mathrm{s}, \mathrm{t})=\sum_{i} t_{i} w_{i o} / \sum_{r} s_{i} z_{r o}$

subject to

$\begin{array}{lr}\sum_{i} t_{i} w_{i j} / \sum_{r} S_{r} z_{r j} \geq 1, & \text { for } \mathrm{j}=1,2, \ldots, 6 \\ \mathrm{~s}_{\mathrm{r}}, \mathrm{t}_{\mathrm{i}} \geq 0, & \text { for all } i \text { and } r\end{array}$

For measuring economic efficiency, the input variables are gross capital formation and labor force, while the output variable is GDP. In addition, for measuring energy efficiency, the input variables are electric power consumption and energy use, while the output variable is $\mathrm{CO} 2$ emissions. For economic efficiency the objective function is of maximization. The idea is that we use the minimum amount of inputs (gross capital formation and labor force) to produce the maximum amount of output (GDP). For energy efficiency the objective function is of minimization. Here, the idea is to minimize the output (CO2 emissions) on the use of inputs (electric power consumption and energy use). Further the study plans to compute a composite index by aggregating economic and energy efficiency indicators. As indicated by Zhou et al. (2008) and Cook and Seiford (2009) and Song et al. (2012) Data Envelopment Analysis (DEA) had been widely implemented in the context of environmental index. The idea starts with the inclusion of undesirable outputs into production. Any production activity will certainly generate undesirable outputs as offshoot of desirable outputs. As an example, carbon dioxide emission is inevitable when oil is burned to generate electricity. DEA models are commonly used to calculate economic and energy efficiency for countries. 
The study plans to conduct the multi-component DEA model devised by Valadkhani et al. (2015). The model determines the relative efficiency for homogeneous decision-making units (DMUs) with reference to several inputs and several outputs. These inputs and outputs could be both desirable and undesirable. In the model applied here, the DMU is represented by six GCC countries. Each DMU has two aspects: economic efficiency and energy efficiency. The first aspect denotes the utilization of economic resources and the second aspects denotes the usage of energy in each country. Economic efficiency has two inputs which lead to a desirable output. In the model proposed by Valadkhani et al. (2015) the concept of economic efficiency was based on Banker et al. (1984) and energy efficiency was based on Kuosmanen (2005). This study, in the process of developing a country level efficiency index, breaks overall efficiency into economic and energy aspects. This model adheres to aggregation indication property which implies that a country is efficient only when it is efficient in both the aspects of economy and energy. This model also satisfies numerous requirements like completeness, unit invariance, and strong monotonicity. These are essential elements of any ideal efficiency measure. For the analysis of data, DEA Online Software (DEAOS) was used to calculate the efficiency scores of all the countries, based on Basic Radial Models (Envelopment Forms), Input Oriented, Constant Returns to Scale (CRS). Further, to estimate the relationship between energy efficiency and economic efficiency in the GCC states, simple linear regression is perfomed on the average scores of the GCC states using EViews. Energy efficiency scores are the independent variables and economic efficiency is the dependent variable. Model testing is also performed for testing for serial correlation, normality and heteroscedasticity using Breusch-Godfrey Serial Correlation LM Test, Jarque-Bera, Breusch-Pagan-Godfrey respectively.

\section{Analysis}

The economic efficiency is calculated for all the six GCC states. Capital and labor are the inputs and GDP is the output. Saudi Arabia has the highest efficiency score of 0.94, closely followed by Qatar (0.92), Kuwait (0.89), Bahrain (0.83), Oman (0.81) and UAE (0.67). There is a huge gap between the economic efficiency scores of Saudi Arabia and UAE. Next, the environmental efficiency scores are calculated using $\mathrm{CO} 2$ emissions as output and electric power consumption and energy as input. Again, the highest efficiency score is for Saudi Arabia (0.91) followed by Oman (0.87), Kuwait and Bahrain have a tie for the $3^{\text {rd }}$ position with a score of 0.74 . Finally, the laggards are UAE (0.65) and Qatar $(0.62)$. Again, there is a huge gap between the best and the worst performers. The case of two countries is worth mentioning. Qatar was ranked second in economic efficiency while it ranked sixth in economic efficiency. Oman was ranked fifth in economic efficiency while it was ranked second in environmental efficiency. Finally, an average of economic and environmental efficiency is taken to compute the composite index. Saudi Arabia has the first place followed by Oman, Kuwait, Bahrain, Qatar and UAE (Table A3). In terms of economic efficiency, Saudi Arabia, Qatar and Kuwait are above the GCC average while Bahrain, Oman and UAE are below the GCC average. In terms of energy efficiency, Saudi Arabia and Oman are above the GCC average while Kuwait, Bahrain UAE and Qatar are below the GCC average. A comprehensive view of the composite efficiency scores can be taken from the figure below. The farther a country is from the center, the more efficient it is. The results of the regression between economic efficiency score and energy efficiency scores are as follows: Economic efficiency $=1.30-(0.62)$ Energy efficiency. The R-squared is equal to 0.96 , which is significant. The t-statistic for the slope coefficient is -17.17 and has a probability value of 0.00 which signifies that the slope coefficient is significantly different from zero and is significant. This denotes that there was a negative relationship between energy and economic efficiency. A one unit decrease in energy efficiency leads to an increase of 0.62 units of economic efficiency (Table A4). The residuals are normally distributed, as the Jarque-Bera test has a value of 0.42 and the corresponding probability vale is 0.81 . This leads to the acceptance of the null hypothesis that the residuals are normally distributed. The Breusch-Pagan-Godfrey test for Heteroskedasticity has a corresponding probability value of 0.38 . The Breusch-Godfrey LM test for Serial Correlation also has corresponding probability value of 0.36 (Table 5). This accepts the null hypothesis of no serial correlation. 

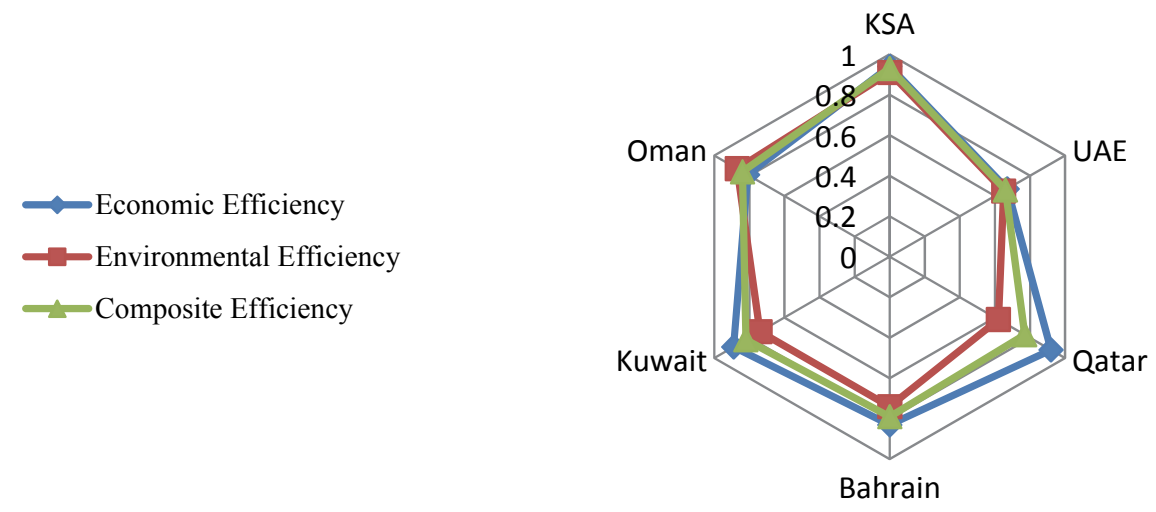

Fig. 1. Composite efficiency of GCC states

\section{Conclusion}

This study fills the gap in the literature as there is no any recent studies attempting to measure the energy efficiency of the GCC states. The study argues that economic efficiency and energy efficiency should be seen together. Oman, which was ranked $5^{\text {th }}$ in terms of economic efficiency and $2^{\text {nd }}$ in terms of energy efficiency, was finally at $2^{\text {nd }}$ position in the composite index. Similarly, Qatar which is ranked $2^{\text {nd }}$ in terms of economic efficiency got $5^{\text {th }}$ position in the composite efficiency moving to $6^{\text {th }}$ position in environmental efficiency. The composite index which is an average of both the two indices show that countries efficiency scores change for Oman and Qatar when energy efficiency is incorporated into economic efficiency. On the other hand, there is no change for the remaining four countries namely Saudi Arabia, Bahrain, Kuwait and UAE. This also goes against some of the previous studies which took all the six GCC states as one and found that the energy usage and challenges are same.

The results of regression analysis between economic efficiency and energy efficiency indicate that the two efficiencies are inversely related. This in a sense supports that energy is a limiting factor to economic growth. This also goes against the conclusion of some previous studies which opine that these GCC states need not forgo economic growth to reduce emissions. The results here indicate that a worsening of energy efficiency has a positive impact on economic efficiency. A probable reason for this could be the abundance of energy sources and its cheap pricing which has led to the use of non-efficient energy production process. Residual analysis also shows that the error terms are normally distributed and free from the problems of serial correlation and heteroscedasticity. Changing the production structure and technology to energy efficient measures is not an easy option. Also, it cannot be achieved in a short span of time that too particularly when these states are actively pursuing diversification. But, conserving energy used by the household sector can be more easily achieved. The GCC states have recently revised their energy prices to promote conservation. This household sector at the moment consumes around $18 \%$ of total energy consumption and $43 \%$ of total energy consumption. Switching to an alternative like solar energy is a viable option. Awareness programs can also be helpful. All the six GCC countries work together towards developing strategic plans to achieve both economic and environmental goals. They can learn from the best practices performed by member countries and share and support ideas and mechanisms to achieve sustainable development. A detailed analysis of the economies structure in terms of relative contribution of industrial sector and service sector is warranted to further investigate the economic efficiency. Also, the strategies adopted by each state needs to be assessed to understand which methods can lead to energy efficiency.

\section{References}

Al-Iriani, M. A. (2006). Energy-GDP relationship revisited: an example from GCC countries using panel causality. Energy policy, 34(17), 3342-3350. 
Al-Sarihi, A. (2018). Prospects for climate change integration into GCC economic diversification strategies.

Ang, J. B. (2008). Economic development, pollutant emissions and energy consumption in Malaysia. Journal of Policy Modeling, 30(2), 271-278.

Apergis, N., \& Payne, J. E. (2009). CO2 emissions, energy usage, and output in Central America. Energy Policy, 37(8), 3282-3286.

Arouri, M. E. H., Youssef, A. B., M'henni, H., \& Rault, C. (2012). Energy consumption, economic growth and CO2 emissions in Middle East and North African countries. Energy policy, 45, 342-349.

Banker, R. D., Charnes, A., \& Cooper, W. W. (1984). Some models for estimating technical and scale inefficiencies in data envelopment analysis. Management Science, 30(9), 1078-1092.

Cook, W. D., \& Seiford, L. M. (2009). Data envelopment analysis (DEA)-Thirty years on. European journal of operational research, 192(1), 1-17.

Charnes, A. C. T. C., Clark, C. T., Cooper, W. W., \& Golany, B. (1984). A developmental study of data envelopment analysis in measuring the efficiency of maintenance units in the US air forces. Annals of Operations Research, 2(1), 95-112.

Deloitte (2015). Energy on demand: the future of GCC energy efficiency Middle East Energy and Resources Managing scarcity for the future, 1-6.

https://www2.deloitte.com/content/dam/Deloitte/xe/Documents/energy-resources/meerwhitepaperseries/me er_whitepaper4_energy_efficiency.pdf

Fang, Z., \& Chang, Y. (2016). Energy, human capital and economic growth in Asia Pacific countriesEvidence from a panel cointegration and causality analysis. Energy Economics, 56, 177-184.

Jaunky, V. C. (2011). The CO2 emissions-income nexus: evidence from rich countries. Energy Policy, 39(3), 1228-1240.

Halicioglu, F. (2009). An econometric study of CO2 emissions, energy consumption, income and foreign trade in Turkey. Energy Policy, 37(3), 1156-1164.

Howarth, N., Galeotti, M., Lanza, A., \& Dubey, K. (2017). Economic development and energy consumption in the GCC: an international sectoral analysis. Energy Transitions, 1(2), 6.

Hormann, M., Kuntze, J. C., \& Dib, J. (2012). Delivering on the Energy Efficiency Promise in the Middle East. Middle East, 1, 1-2.

Kuosmanen, T. (2005). Weak disposability in nonparametric production analysis with undesirable outputs. American Journal of Agricultural Economics, 87(4), 1077-1082.

Mehrara, M. (2007). Energy consumption and economic growth: the case of oil exporting countries. Energy policy, 35(5), 2939-2945.

Narayan, P. K., \& Narayan, S. (2010). Carbon dioxide emissions and economic growth: Panel data evidence from developing countries. Energy policy, 38(1), 661-666.

Omri, A. (2013). CO2 emissions, energy consumption and economic growth nexus in MENA countries: Evidence from simultaneous equations models. Energy economics, 40, 657-664.

Pablo-Romero, M. D. P., \& Sánchez-Braza, A. (2015). Productive energy use and economic growth: Energy, physical and human capital relationships. Energy Economics, 49, 420-429.

Ramanathan, R. (2005). An analysis of energy consumption and carbon dioxide emissions in countries of the Middle East and North Africa. Energy, 30(15), 2831-2842.

Sabouni, R., Blaschke, C.F., Bkayrat, R., \& Gentil, S. (2017). Energy Efficiency in the GCC: Status and Outlook, Clean Energy Business Council MENA, 1-13. Available on the Internet: http://cebcmena.com/wp-content/uploads/2018/03/CEBC-Energy-Efficiency-in-the-GCC-January-2018REV2.pdf

Sakhrieh, A. (2016). Energy Analysis for GCC Countries, Global Conference on Renewables and Energy Efficiency for Desert Regions, Amman-Jordan, April 4th - 6th, 1-4.

Solow, R. M. (1956). A contribution to the theory of economic growth. The quarterly journal of economics, 70(1), 65-94.

Solow, R. M. (1974). Intergenerational equity and exhaustible resources. The review of economic studies, 41, 29-45. 
Song, M., An, Q., Zhang, W., Wang, Z., \& Wu, J. (2012). Environmental efficiency evaluation based on data envelopment analysis: a review. Renewable and Sustainable Energy Reviews, 16(7), 4465-4469.

Stern, D. I. (1993). Energy and economic growth in the USA: a multivariate approach. Energy economics, 15(2), 137-150.

Sultan, N. (2012). The Energy Challenge of the Post-Oil GCC. Workshop Title: Energy Challenges in the Gulf, Workshop No. 12, 3rd Gulf Research Meeting (11-14 July) University of Cambridge.

Taylor, B. W. (2013). Introduction to management science. Edition 11. New Jersy: Published by Pearson Education, Inc.

Ucan, O.; Aricioglu, E.; Yucel, F. (2014). Energy consumption and economic growth nexus: Evidence from developed countries in Europe, International Journal of Energy Economics and Policy, 4(3), 411-419.

Valadkhani, A., Roshdi, I., \& Smyth, R. (2015). A multicomponent DEA approach to measure the economic and energy efficiencies of OECD countries (No. 09-15). Monash University, Department of Economics.

WRI. (2014). WRI's Climate Analysis Indicators Tool CAIT 2.0 [Online]. Washington, DC: WRI. Available: http://cait2.wri.org

Zhou, P., Ang, B. W., \& Poh, K. L. (2008). A survey of data envelopment analysis in energy and environmental studies. European journal of operational research, 189(1), 1-18.

\section{Appendix}

Table A.1

Descriptive statistics

\begin{tabular}{|c|c|c|c|c|c|c|}
\hline Country & Variable & Mean & Standard Deviation & Minimum & Maximum & $\mathrm{CV} \%$ \\
\hline \multirow{6}{*}{$\begin{array}{c}\text { Saudi } \\
\text { Arabia }\end{array}$} & Labor force, total & 8913645 & 1906988 & 6403495 & 12391353 & 21 \\
\hline & Gross capital formation (current US\$) & 113096995274 & 66938135675 & 36133485333 & 217455168107 & 59 \\
\hline & GDP, PPP (constant 2011 international \$) & 1163208472648 & 221401190348 & 858612755959 & 1537557122109 & 19 \\
\hline & $\mathrm{CO} 2$ emissions (kt) & 432418 & 98032 & 296935 & 601047 & 23 \\
\hline & Electric power consumption ( $\mathrm{kWh}$ per capita) & 7210 & 1137 & 5638 & 9444 & 16 \\
\hline & Energy use (kg of oil equivalent per capita) & 5764 & 794 & 4713 & 6937 & 14 \\
\hline \multirow{6}{*}{ Bahrain } & Labor force, total & 550333 & 170115 & 305448 & 758820 & 31 \\
\hline & Gross capital formation (current US\$) & 5498410461 & 2824914400 & 1410118351 & 9042819149 & 51 \\
\hline & GDP, PPP (constant 2011 international \$) & 43359164612 & 9649777151 & 29869327646 & 58584095087 & 22 \\
\hline & $\mathrm{CO} 2$ emissions (kt) & 23491 & 6362 & 13927 & 31338 & 27 \\
\hline & Electric power consumption ( $\mathrm{kWh}$ per capita) & 19358 & 1275 & 17460 & 21508 & 7 \\
\hline & Energy use ( $\mathrm{kg}$ of oil equivalent per capita) & 10980 & 741 & 9658 & 11989 & 7 \\
\hline \multirow{6}{*}{ Kuwait } & Labor force, total & 1403735 & 372609 & 987618 & 2100775 & 27 \\
\hline & Gross capital formation (current US\$) & 16503829432 & 7965118905 & 4022164276 & 26493323963 & 48 \\
\hline & GDP, PPP (constant 2011 international \$) & 215913040122 & 44628083433 & 143388170990 & 267917846910 & 21 \\
\hline & $\mathrm{CO} 2$ emissions (kt) & 77348 & 16306 & 53560 & 102335 & 21 \\
\hline & Electric power consumption ( $\mathrm{kWh}$ per capita) & 16030 & 1091 & 14028 & 17739 & 7 \\
\hline & Energy use ( $\mathrm{kg}$ of oil equivalent per capita) & 10275 & 769 & 8957 & 11544 & 7 \\
\hline \multirow{6}{*}{ Oman } & Labor force, total & 1224599 & 424147 & 786011 & 2097547 & 35 \\
\hline & Gross capital formation (current US\$) & 12341427169 & 7323514462 & 2998439532 & 23536824967 & 59 \\
\hline & GDP, PPP (constant 2011 international \$) & 122082827088 & 21405886335 & 99713483631 & 159556704688 & 18 \\
\hline & $\mathrm{CO} 2$ emissions (kt) & 40546 & 14076 & 20286 & 61378 & 35 \\
\hline & Electric power consumption ( $\mathrm{kWh}$ per capita) & 4704 & 1164 & 3202 & 6554 & 25 \\
\hline & Energy use (kg of oil equivalent per capita) & 5172 & 1428 & 3337 & 6833 & 28 \\
\hline \multirow{6}{*}{ UAE } & Labor force, total & 4139193 & 1818875 & 1771872 & 6367953 & 44 \\
\hline & Gross capital formation (current US\$) & 57974315295 & 25339849059 & 23247651464 & 84117452689 & 44 \\
\hline & GDP, PPP (constant 2011 international \$) & 450321721927 & 82867015722 & 325665324250 & 581686509201 & 18 \\
\hline & $\mathrm{CO} 2$ emissions (kt) & 140296 & 35340 & 84704 & 211370 & 25 \\
\hline & Electric power consumption ( $\mathrm{kWh}$ per capita) & 11583 & 624 & 10612 & 12401 & 5 \\
\hline & Energy use ( $\mathrm{kg}$ of oil equivalent per capita) & 9034 & 1514 & 7418 & 12087 & 17 \\
\hline \multirow{6}{*}{ Qatar } & Labor force, total & 930996 & 526888 & 338862 & 1778478 & 57 \\
\hline & Gross capital formation (current US\$) & 30633772894 & 21117431651 & 3578846154 & 65559065934 & 69 \\
\hline & GDP, PPP (constant 2011 international \$) & 158394586715 & 83701937920 & 64156673602 & 286972440752 & 53 \\
\hline & $\mathrm{CO} 2$ emissions (kt) & 63548 & 21812 & 34730 & 107854 & 34 \\
\hline & Electric power consumption ( $\mathrm{kWh}$ per capita) & 15162 & 653 & 14233 & 16231 & 4 \\
\hline & Energy use ( $\mathrm{kg}$ of oil equivalent per capita) & 18440 & 2003 & 15234 & 21959 & 11 \\
\hline
\end{tabular}


Table A2

Efficiency scores

\begin{tabular}{|c|c|c|c|c|c|c|c|c|c|c|c|c|c|c|c|c|}
\hline Country & 2000 & 2001 & 2002 & 2003 & 2004 & 2005 & 2006 & 2007 & 2008 & 2009 & 2010 & 2011 & 2012 & 2013 & 2014 & Average \\
\hline \multicolumn{17}{|c|}{ Economic efficiency score } \\
\hline KSA & 1.00 & 1.00 & 0.94 & 0.95 & 0.97 & 0.98 & 0.96 & 0.94 & 0.97 & 0.91 & 0.91 & 0.94 & 0.92 & 0.90 & 0.89 & 0.94 \\
\hline Bahrain & 1.00 & 1.00 & 0.93 & 0.91 & 0.89 & 0.87 & 0.83 & 0.81 & 0.78 & 0.74 & 0.72 & 0.72 & 0.74 & 0.77 & 0.79 & 0.83 \\
\hline Kuwait & 1.00 & 0.95 & 0.91 & 1.00 & 1.00 & 1.00 & 1.00 & 1.00 & 0.95 & 0.83 & 0.75 & 0.77 & 0.77 & 0.72 & 0.68 & 0.89 \\
\hline Oman & 1.00 & 1.00 & 0.96 & 0.89 & 0.86 & 0.84 & 0.83 & 0.81 & 0.81 & 0.79 & 0.76 & 0.68 & 0.67 & 0.63 & 0.59 & 0.81 \\
\hline Qatar & 1.00 & 0.98 & 0.99 & 0.94 & 1.00 & 0.92 & 0.95 & 0.91 & 0.88 & 0.84 & 0.88 & 0.91 & 0.89 & 0.87 & 0.85 & 0.92 \\
\hline UAE & 1.00 & 0.94 & 0.89 & 0.89 & 0.86 & 0.79 & 0.74 & 0.64 & 0.57 & 0.48 & 0.44 & 0.45 & 0.46 & 0.48 & 0.50 & 0.67 \\
\hline \multicolumn{17}{|c|}{ Energy efficiency scores } \\
\hline KSA & 0.79 & 0.76 & 0.82 & 0.78 & 0.94 & 0.93 & 0.96 & 0.85 & 0.90 & 0.95 & 0.98 & 0.95 & 1.00 & 0.97 & 1.00 & 0.91 \\
\hline Bahrain & 0.56 & 0.41 & 0.47 & 0.50 & 0.55 & 0.55 & 0.54 & 0.79 & 0.96 & 0.96 & 0.97 & 0.96 & 0.92 & 1.00 & 0.98 & 0.74 \\
\hline Kuwait & 0.58 & 0.60 & 0.59 & 0.57 & 0.59 & 0.64 & 0.65 & 0.69 & 0.74 & 0.80 & 0.82 & 0.88 & 0.98 & 1.00 & 1.00 & 0.74 \\
\hline Oman & 0.70 & 0.62 & 0.76 & 0.95 & 0.78 & 0.79 & 0.95 & 1.00 & 0.91 & 0.80 & 0.88 & 0.94 & 0.97 & 1.00 & 1.00 & 0.87 \\
\hline Qatar & 0.34 & 0.39 & 0.37 & 0.36 & 0.38 & 0.47 & 0.57 & 0.59 & 0.68 & 0.78 & 0.80 & 0.86 & 0.90 & 0.84 & 1.00 & 0.62 \\
\hline UAE & 0.49 & 0.45 & 0.36 & 0.46 & 0.51 & 0.50 & 0.56 & 0.62 & 0.72 & 0.82 & 0.79 & 0.83 & 0.88 & 0.83 & 1.00 & 0.65 \\
\hline
\end{tabular}

Table A3

Ranking as per efficiency scores

\begin{tabular}{cccccccc}
\hline & \multicolumn{2}{c}{ Economy } & & Energy & \multicolumn{2}{c}{ Composite Efficiency } \\
\cline { 2 - 7 } & Score & Rank & Score & Rank & Score & Rank \\
\hline KSA & 0.94 & 1 & 0.91 & 1 & 2 & 0.93 & 2 \\
Oman & 0.81 & 5 & 0.87 & $3 / 4$ & 0.82 & 3 \\
Kuwait & 0.89 & 3 & 0.74 & $3 / 4$ & 0.79 & 4 \\
Bahrain & 0.83 & 4 & 0.74 & 6 & 0.77 & 5 \\
Qatar & 0.92 & 2 & 0.62 & 5 & 0.66 & 6 \\
UAE & 0.67 & 6 & 0.65 & & 0.80 & \\
GCC average & 0.84 & & 0.76 & & & \\
\hline
\end{tabular}

Table A4

$\underline{\text { Regression analysis }}$

\begin{tabular}{|c|c|c|c|c|}
\hline & Dep & $\begin{array}{l}\text { ECONOM } \\
\text { Squares } \\
\text { ations: } 15\end{array}$ & & \\
\hline Variable & Coefficient & Std. Error & t-Statistic & Prob. \\
\hline $\mathrm{C}$ & 1.31 & 0.03 & 47.30 & 0.00 \\
\hline ENERGY & -0.62 & 0.04 & -17.17 & 0.00 \\
\hline R-squared & \multicolumn{4}{|c|}{0.96} \\
\hline F-statistic & \multicolumn{4}{|c|}{294.92} \\
\hline Prob(F-statistic) & \multicolumn{4}{|c|}{0.00} \\
\hline
\end{tabular}

Table A5

Residual Analysis

\begin{tabular}{|c|c|c|c|}
\hline \multicolumn{4}{|c|}{ Normality } \\
\hline Jarque-Bera & & Probability & 0.81 \\
\hline \multicolumn{4}{|c|}{ Heteroskedasticity Test: Breusch-Pagan-Godfrey } \\
\hline F-statistic & 0.679945 & Prob. $F(1,13)$ & 0.4245 \\
\hline Obs*R-squared & 0.745557 & Prob. Chi-Square(1) & 0.3879 \\
\hline Scaled explained SS & 0.500406 & Prob. Chi-Square(1) & 0.4793 \\
\hline \multicolumn{4}{|c|}{ Breusch-Godfrey Serial Correlation LM Test: } \\
\hline F-statistic & 0.855684 & Prob. $F(2,11)$ & 0.4514 \\
\hline Obs*R-squared & 2.019493 & Prob. Chi-Square(2) & 0.3643 \\
\hline
\end{tabular}


(C) 2019 by the authors; licensee Growing Science, Canada. This is an open access article distributed under the terms and conditions of the Creative Commons Attribution (CCBY) license (http://creativecommons.org/licenses/by/4.0/). 